\title{
CORRESPONDENCE
}

\section{Health hazards while fishing in heavy weather}

Editor-Fishing crews are frequently exposed to heavy physical stress and strain while working, and the risk of death is high. ${ }^{2}$ Fishing keeps going in all weathers, but the hazards to health, arising during work in heavy weather, have not received much notice. After a series of violent storms in January 1993 we were asked to study this problem more closely. A detailed questionnaire was devised to elucidate the level of exposure and the mens' own impression of the health hazards involved. Thirty nine fishermen taking part in a conference in December 1993 filled in the questionnaire. They were asked to answer questions regarding the worst situations they had ever experienced. Their mean (range) experience as fishermen was $21(5-45)$ years. All were employed as ordinary members of crew, although eight had acted temporarily as substitute skippers. The respondents' mean age was $43(26-66)$. The types of boat most had served on were Danish seiners of 20-60 tonnes, gill netters of 10-45 tonnes and trawlers from 20 to 300 tonnes. The waters most frequently fished were in the North Sea.

The worst gales they had fished in were estimated to have been from 10 to $40 \mathrm{~m} / \mathrm{s}$ (78 knots). These worst experiences were most frequent in autumn and winter. The vessels were frequently too small for the seas and the wind conditions, with a great deal of rolling as a consequence. Some respondents wrote that there was not enough room to work in and that the work was badly organised. Among the dangerous situations mentioned were sailing in and out of harbour, freak waves, and icing up. Seas sometimes break right over the ship, and it is difficult to hang on. About three quarters of them thought that work was harder now. Casting and hauling in gear were the hardest tasks. Seasickness was no particular problem in heavy weather, but some of them complained of headaches, dizziness, and tension. Over half of them found it difficult to sleep or rest because of rolling, noise, and vibration. A few wrote that they had been frightened during hurricanes, when freak waves came over, or when casting or hauling in gear. There were frequent complaints about the musculoskeletal system, including back trouble.

About a third thought that fishing in heavy weather could be a reason for giving the job up. Families, too, expressed anxiety about fishing. When asked what ought to be done, several people said that the quota system should be changed and that the parlous financial state of the fishing industry ought to be improved. The fishermen also said that there ought to be a limit to the kind of weather they were allowed to fish in-for example wind speeds of around $20-25 \mathrm{~m} / \mathrm{s}$ (40-50 knots). The hazards arising from fishing in heavy weather come on top of the stresses and strains already existing. Lack of sleep and rest affect safety at sea and increase the risk of injury. The body is espe- cially stressed by the vessel's rolling, and there is a risk of damage to the lumbar region even in good weather. ${ }^{3}$ This, together with the other health hazards, force one to the conclusion that fishing in very heavy weather should be avoided. As well as which, many ships are lost or badly damaged every year as a result of the enormous forces of the sea. Large numbers of ships have been laid up since 1987, while at the same time the number of days spent fishing by the remainder of the fleet has increased. ${ }^{4}$ This confirms the fishermens' own impression that they are having to go out in heavy weather more often than before. Reduced scope for fishing also forces crews to go farther out to sea in smaller vessels which were not built for it. ${ }^{5}$ Improvements in the weather forecasting system would help, but the entire way in which the fishing industry is organised must be regarded as a contributory factor to the current situation. The quota system must be amended to take special account of health and safety in the working environment aboard fishing boats. ${ }^{6}$ Individual transferable quotas have recently been proposed to make it unnecessary for fishermen to go out in all weathers. ${ }^{7}$ Classification of vessels by the kind of conditions they are fit for would also be a relevant move. This small pilot study has only given a superficial impression of the workloads and more detailed studies are necessary. This applies not only to the physical strain, but also to the mental strain, both short term and long term.

I thank Mr E H Pedersen, fishing technologist and Ms $G$ van der Horst, psychologist for their valuable assistance.

OLAF C JENSEN Institute of Maritime Medicine, South Futland University Centre, Niels Bohrs Vej 9, DK-6700 Denmark

1 Schilling RSF. Hazards of deep-sea fishing. $\mathrm{Br}$ F Ind Med 1971;28:27-35.

$2 \mathrm{NIOSH}$ alert: request for assistance in preventing drownings of commercial fishermen. MMWR Morb Mortal Wkly Rep 1994;43: 449-50.

3 Törner $M$. Musculoskeletal stress in fishery causes, effects, and preventive measures. Göteborg, Sweden: University of Göteborg, 1991. [Dissertation.]

4 Frost H, Lanters R, Smit J, Sparre P. An appraisal of the effects of the decommissioning scheme in the case of Denmark and the Netherlands. Esbjerg: South Jutland University Centre, 1995 .

5 Hopper AG, Dean AJ. Safety in fishing-learning from experience. Safety Science 1992;15: 249-71.

6 Oliver $\mathrm{T}$, ed. Lives may have been saved. Fishing News Weekly 3 January 1992

7 Strutt I, ed. End the race to fish. Fishing News International December 1995.

\section{Upper aerodigestive cancer in battery} manufacturers and steel workers exposed to mineral acid mists

Editor-Coggon et al ${ }^{1}$ conclude that their findings are consistent with those of other studies indicating a hazard of upper aerodigestive cancer from acid mists. In fact, concern from acid mists has focused primarily on respiratory tract cancer and the findings in this article cast doubt on the conclusions of previous studies. The standardised mortality ratios in the cohort study were 0.48 and 0.98 respectively for cancers of the larynx and lung and there were no cases of nasopharyngeal cancer among exposed workers. This is in notable contrast to odds ratios of up to 13 for cancer of the larynx reported in cited articles.

In the nested case-control study it is interesting to note that all additional cases that were identified were exposed workers and no additional cases were found among unexposed workers. Even so, few additional cases of respiratory tract cancer were identified. The most frequently identified case was that of lip cancer (three live cases). Other living cases included cancers of the retromolar area (1), nasopharynx (1), larynx (1), and nasal sinus (1). Combining cases such as cancer of the lip and mouth with those of the larynx and nasopharynx for analysis seems to be a questionable practice. This is especially true for cancer of the lip which has different risk factors such as sun exposure and pipe smoking. Excluding the cases of cancer of the lip from the analysis shown in their table 5 would almost certainly result in an odds ratio near unity rather than the $2 \cdot 0$ they report for the group with five years or more exposure to high levels of acid mist. Also, there are four upper aerodigestive cancers identified in the non-exposed workers in table 3 but only three are reported in tables 4 and 5. It seems that one of the nonexposed cases was mistakenly transferred to the exposed category. Switching this case back to the proper category would also cause the odds ratio to be closer to unity.

As well as the negative findings in the cohort study there are other reasons to doubt the evidence used by the International Agency for Research on Cancer (IARC) for their classification of "occupational exposure to strong inorganic acid mist containing sulphuric acid" as a known human carcinogen. The case control study reporting the highest odds ratios for sulphuric acid mist and cancer of the larynx was the article of Soskolne et al. They reported odds ratios for no/low, medium, and high exposure as $1 \cdot 0,4 \cdot 6$, and 13.4. ${ }^{2}$ However, when this same data were reanalysed with total estimated cumulative dose, instead of estimated average annual dose for years exposed, the odds ratios were $1.0,0.58$, and 0.70 respectively. When the results of such studies seem to be so radically different depending on the type of analysis used one should question the validity of the positive findings. This is especially important for the Soskolne study where use of the more traditional cumulative dose yields negative results. All of the other studies used by IARC had significant flaws ranging from lack of exposure verification or measurement, confounding exposures such as nickel, alkyl sulphates, asbestos, etc and inadequate control for smoking and alcohol consumption and no control for the synergistic interaction of smoking and heavy alcohol use.

$$
\begin{array}{r}
\text { JAMES A HATHAWAY } \\
\text { Rhone-Poulenc, } \\
\text { CN } 5255, \\
\text { Princeton, NF } 08543,
\end{array}
$$

1 Coggon D, Pannett B, Wield G. Upper aerodigestive cancer in battery manufacturers and steel workers exposed to mineral acid mists. Occup Environ Med 1996;53:445-9.

2 Soskolne CL, Zeighami EA, Hanis NM, Kupper LL, Herrmann $\mathrm{N}$, Amsel J, et al. Laryngeal cancer and occupational exposure to sulfuric acid. Am $₹$ Epidemiol 1984;120: 358-69. 
3 Suarez-Almazor ME, Soskolne CL, Fung K, Jhangri G. Empirical assessment of the effect of different summary worklife exposure measures on the estimation of risk in case-refersures on the estimation of risk in case-refer-
ent studies of occupational cancer. Scand $\mathcal{F}$ Work Environ Health 1992;18:233-41.

Authors' reply - Hathaway draws attention to an apparent inconsistency in the classification of exposures in our study. This arose because, as explained in the paper, the method for assigning exposures in the nested case-control study differed from that in the cohort analysis. In the cohort analysis, factory specific job exposure matrices were used to classify people as never, possibly, or definitely exposed to acid mists. In the nested case-control study exposures were classified as zero, low, high, or uncertain, taking into account not only the jobs in which men had worked, but also the periods during which men had been employed. We questioned staff at the factories about these jobs in more detail than would have been practical for the full cohort. Among other things this caused one deceased case, originally classed as unexposed, to be assigned to the uncertain category; and another, whose exposure had been uncertain, to be classed as having low exposure.

We must stress that all exposures in the nested case-control study were assigned blind to the case or control status of the subject. Because they were assessed from more detailed information than could be incorporated into the cohort analysis, they should be more reliable.

Hathaway also questions our inclusion of cancers of the lip and mouth with those of the larynx and nasopharynx. This decision was made before the analysis was carried out, and was based on an assumption that if acids cause cancer of the upper aerodigestive tract, the most likely mechanism is by an irritant effect. High exposure to acid mists is known to cause dental erosion, and it seemed natural to include cancers of the lip and mouth. Hathaway points out that lip cancer is caused by sun exposure and pipe smoking, but there is no reason to think that within the workforce studied, men exposed to acid mists would have had higher exposure to sunlight or pipe smoking.

The statistical power of our study was limited, but we stand by our conclusion. The findings are consistent with those of other studies indicating a hazard of aerodigestive cancer from acid mists, but they suggest that any risk from exposure to sulphuric acid and hydrochloric acid below $1 \mathrm{mg} / \mathrm{m}^{3}$ is small.

DAVID COGGON BRIAN PANNETT GRAHAM WIELD MRC Environmental Epidemiology Unit, Southampton General Hospital,

Do occupational exposures in nuclear refineries contribute to mortality from brain cancer?

Editor-Mortality from brain cancer has been found more often than expected in several nuclear processing plants. ${ }^{1}$ Exposure to chemicals and radiation were examined, one by one, but each alone was not the causative agent of the disease. ${ }^{2-4}$ The possibility of an association between brain cancer and exposure to electromagnetic fields has been examined in several recent studies, ${ }^{5}$ but defi- nite conclusions about a causal relation have not yet been reached.

Brain cancer was noticed to occur more frequently than expected in uranium mill workers in Ontario (observed 5, expected $1 \cdot 12$, standardised mortality ratio (SMR) $446,95 \%$ confidence interval $(95 \% \mathrm{CI}): 147$ to 1054). This finding was unexpected. These 1190 uranium millers were included in a larger study of underground uranium miners to find out whether exposure to uranium dust in the mills could have increased mortality from kidney disease. The SMRs for all causes, all cancer, and most other specific cancer sites were below 100 for the uranium mill workers. No brain cancers were found (expected $=1.51$ ) in men who worked in other mills in Ontario where ores such as gold, nickel, or zinc were processed. Nor was an excess of brain cancer found in Ontario uranium miners (observed 14, expected 23.72, SMR 59). An excess of mortality from brain cancer has also been found in men who worked in tank houses where nickel is electrolytically refined (observed 8, expected $2 \cdot 19$ ).

Two of the deaths from brain cancer in the Ontario uranium mill workers occurred in men under the age of 35; the other three occurred in men over 55. Two of the cancers were glioblastoma multiforme, one a glioma, one a medulloblastoma, a rare tumour occurring in children and young adults, and the histology of the other brain tumour was unspecified. The work histories available to us were not detailed enough to identify characteristics in which the workers who died of brain cancer differed from the whole cohort. Three of the men who died of brain cancer did not work elsewhere in the mining industry in Ontario. One worked underground in a uranium mine and another was a painter for 28 months and gold mill worker for 141 months. Employments in the uranium mills ranged from four months to 74 months for these five men. Four of the five deaths from brain cancer occurred less than 10 years after the men last worked in the uranium mills. The date of diagnosis of brain cancer was not recorded on the death certificate for two men and ranged from two months to 6.5 years before death for the other three men.

Exposure records for external $\gamma$ radiation have been included in the National Dose Registry ${ }^{7}$ since the routine monitoring of the radiation exposures of uranium mine and mill workers was begun in 1981 . We obtained exposure records from the National Dose Registry for $92 \%$ of the 1190 Ontario uranium mill workers. The average lifetime exposure to radon from all occupational sources was 20 working level months and the average cumulative external $\gamma$ radiation exposure between 1981 and 1995 was $17 \mathrm{mSv}$. All of the men who died of brain cancer began working in the Ontario uranium mills in the late 1950 s before external $\gamma$ levels were routinely measured and recorded in the National Dose Registry. Exposure levels for all workers exposed to radiation in Canada have decreased since the 1950s but deciding whether this also occurred for uranium millers is difficult. In any case, the uranium millers' low levels of exposure to external $\gamma$ radiation reflect the low levels of radioactive elements in the uranium ores mined in Ontario. Exposure to radon has not been associated with brain cancer, ${ }^{8}$ but several studies have shown an association between brain cancer and exposure to $\gamma$ radiation. ${ }^{9}$ However, no association between brain cancer and exposure to radiation has yet been found in the survivors of the atomic bombings of Nagasaki and Hiroshima.

Recently, electromagnetic fields and extremely low frequency fields in two Ontario mines were surveyed but no measurements of the intensity of those fields in any of the uranium mills were made. The survey data showed that levels of electromagnetic fields around some heavy duty electrical machinery used in the mining industry was between 1 and $10 \mu \mathrm{T}$ and levels of electromagnetic fields in the electrolytic nickel refineries were much higher. A recent United States study found a significant excess of brain cancer in workers in the highest exposure category. Exposure to magnetic fields two to 10 years before death was most strongly associated with mortality from brain cancer, the relative risk increasing by $1.94 / \mu \mathrm{T}$-year. ${ }^{10}$ This suggests that magnetic fields may act as a tumour promoter. ${ }^{5} \mathrm{~A}$ Canada-France collaborative study found a non-significant increased risk of brain cancer in workers whose cumulative exposure to magnetic fields was above $15.7 \mu \mathrm{T}$-years (odds ratio $1.95,95 \%$ CI 0.76 to 5.0 ) ${ }^{1}$

The question of whether or not the increase in brain tumours in nuclear processing plants is due to occupational exposures remains unanswered. It is unlikely that exposure to radon is directly related to the development of brain cancer as no excess has been found in uranium miners and the exposures in the uranium mills were much lower than in the uranium mines. Neither do the exposures to $\gamma$ radiation seem to be large enough to produce an excess of brain cancer. The exposures to electromagnetic fields, however, may be larger than those found in other studies, in which excesses of brain cancer have been found. The case-control method should be used to investigate exposures that might be associated with brain tumours in nuclear processing plants and electrolytic metal refineries. Electromagnetic fields, radon progeny, $\gamma$ radiation, and exposures to chemicals, including solvents, can be considered in the analysis. Several study populations would need to be combined to get one large enough for a valid statistical analysis.

ROBERT KUSIAK Health and Safery Studies Unit, Occupational Health and Safety Branch, Ontario Ministry of Labour, 400 University Avenue, Toronto, Ontario M7A 1T7 PATRICK ASHMORE National Dose Registry, Radiation Protection Bureau, 775 Brookfield Road, Ottawa, Ontario K1A 1C1 DALSU BARIS

Radiation and Environmental Protection Division, Atomic Energy Control Board, 280 Slater Street,
Ontario KIP 599

Ottawa, Ontario K1P $5 S 9$

Correspondence to: Dr R Kusiak, Occupational Health and Safety Studies Unit, 400 University Avenue, 7th Floor, Toronto, Ontario M7A 1T7, Canada.

1 Alexander V. Brain tumour risk among United States nuclear workers. Occup Med 1991; 6:695-715.

2 Carpenter AV, Flanders WD, Frome EL, Crawford-Brown DJ, Fry SA. CNS cancers and radiation exposure: a case-control study among workers at two nuclear facilities. $f$ Occup Med 1987;29:601-4.

3 Carpenter AV, Flanders WD, Frome EL, Tankersley WG, Fry SA. Chemical expoTankersley WG, Fry SA. Chemical exposures and central nervous system cancers: a case-control study among workers at two 351-62.

4 Carpenter AV, Flanders WD, Frome EL, Cole 